Special Issue of the 8th International Advances in Applied Physics and Materials Science Congress (APMAS 2018)

\title{
Hazardous Waste Recycling: End of Life Tires Case
}

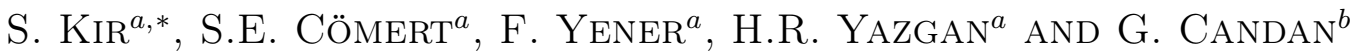 \\ ${ }^{a}$ Sakarya University, Engineering Faculty, Department of Industrial Engineering, Sakarya, Turkey \\ ${ }^{b}$ Sakarya University, Faculty of Political Sciences, Department of Econometrics, Sakarya, Turkey
}

In this study, the ELT recycling process and management system of Turkey were examined. A new mixed integer nonlinear programming model was proposed for the collection, transport, and recycling of the ELT. Since the dimension of the current problem was not suitable for finding the optimum solution, a clustering approach was also proposed. The proposed approach was validated on a case study.

DOI: 10.12693/APhysPolA.135.681

PACS/topics: ELT management, ELT recycling in Turkey, mixed-integer nonlinear programming, clustering analysis

\section{Introduction}

The increase in the amount of waste causes devastating environmental disasters and also reduces natural resources. Energy use, resource consumption, and waste generation in the production activities of enterprises have negative effects on the environment [1]. The rapid increase of wastes, the inadequacy of disposal methods, and the presence of elements that would threaten the lives of the people have made the concept of recycling important [2]. The ELT is currently the most efficacious waste material recycling in the world in solid waste recycling. According to the research, $84 \%$ of the ELT in the world and $95 \%$ in Europe are being recycled. The recycling and recovery of the ELT are provided by the Lifetime Completed Tire Control Regulation in Turkey. There are two major environmental hazards in the places where the ELT are piled and thrown. The first one is the fires and the second is the bugs that find the opportunity to grow easily in these heaps [3]. Harmonious gases are spreading in the atmosphere in tons of places with the fire in the piled areas. In a black cloud like atmosphere, metals such as carbon black, volatile organics, semi-volatile organic compounds, polycyclic hydrocarbons, oils, sulfur oxides, nitrogen oxides, nitrosamines, carbon oxides, volatile particles, and $\mathrm{As}, \mathrm{Cd}, \mathrm{Cr}, \mathrm{Pb}, \mathrm{Zn}, \mathrm{Fe}$ etc. can be found. For these reasons, recycling of tires has become important. Recycling of the ELT is provided by Association of Tire Manufacturers which is known as LASDER in Turkey. In order to determine how much ELT will go to the recycling plants (RPs), LASDER receives demands (in tons) from the RPs since 2012 [4]. All decisions regarding the storage and transport of ELT here are very important in terms of cost. This creates the motivation for our study. In this study, a mixed integer nonlinear programming (MINLP) was proposed for the collection, transport, and recycling of the ELT. As the current problem was large-scale, a clustering analysis method was proposed, too.

\footnotetext{
*corresponding author; e-mail: senas@sakarya.edu.tr
}

\section{Material and methods}

A MINLP model is developed which contains the existing constraints as below:

$$
\begin{aligned}
& Z_{\text {min }}=\operatorname{Cost}\left(\sum_{j=1} \sum_{i=1} \operatorname{ServC}_{i j} \operatorname{DistC}_{i j}\right. \\
& \left.+\sum_{k=1} \sum_{i=1} \text { Service }_{i k} D_{i k}\right) \text {, } \\
& M X_{i} \geq \operatorname{Cap}_{i} \text { for all } i, \\
& \sum_{i=1} \text { Service }_{i k} S_{k} \leq \operatorname{Cap}_{i} \quad \text { for all } k, \\
& \sum_{i=1} \operatorname{Cap}_{i} \leq \sum_{j=1} \operatorname{Dem}_{j} \\
& M X_{i} \geq \text { Service }_{i k} \text { for all } i, k, \\
& M X_{i} \geq \operatorname{ServC}_{i j} \text { for all } i, j, \\
& \operatorname{ServC}_{i j} \geq X_{i} \text { for all } i, j, \\
& \sum_{i=1} X_{i} \leq \text { Nodes } \\
& \text { Service }_{i k}=1 \text { for all } i=k, \\
& \sum_{j=1} \operatorname{ServC}_{i j} \leq 1 \quad \text { for all } i, \\
& \sum_{i=1} \text { Service }_{i k}=1 \text { for all } k, \\
& \sum_{i=1} \operatorname{ServC}_{i j} \operatorname{Cap}_{i} \leq \operatorname{Dem}_{j} \text { for all } j, \\
& X_{i}, \text { ServC }_{i j}, \text { Service }_{i k} \in\{0,1\}, \operatorname{Cap}_{i} \geq 0 .
\end{aligned}
$$

The explanations of the parameters and variables used in the model are as follows: $S_{k}$ - offer of the node $k$; Dem $_{j}$ - demand of $j$-th RP; DistC $i j$ - distance between node $i$ and RP $j ; D_{i k}$ - distance between node $i$ and node $k ; X_{i}$ - if a toll centre is established in node $i$, 
then $X_{i}=1$, other case $X_{i}=0$; $\operatorname{Cap}_{i}-$ if $X_{i}=0$, then $\operatorname{Cap}_{i}=0$, other case $\operatorname{Cap}_{i}>0$; Service $_{i k}$ - if the toll centre $i$ serves to node $k$, Service S $_{i k}=1$, other case Service $_{i k}=0 ;$ ServC $_{i j}$ - if the toll centre $i$ serves the $\operatorname{RP} j$, then $\operatorname{ServC}_{i j}=1$, other case $\mathrm{ServC}_{i j}=0$.

Equation (1) is used to minimize the total transportation cost. Equations (2)-(4) determine the capacity of the toll centers in accordance to the demand or capacity of the nodes and RPs in the nodes. Equations (5)-(7) provide the relationship between the nodes to be established and the RPs to be serviced. Equation (8) provides for the establishment of a maximum of one toll center in all nodes. Equation (9) provides the condition that the toll center should be serviced where it will be established. Equation (10) provides that each toll center can work with at most 1 RPs. Equation (11) provides that each node collects waste rubber only at one toll center. Equation (12) provides that the ELT to be transported to the RPs from the toll centers to be installed in the node do not exceed the demand or capacity of the installation.

The similarities of individuals in our study have been associated with their location in the space. The individuals who are close to each other in position will be in the same cluster. In this respect, Euclidean distance was used as the similarity criterion. The partitioned clustering was chosen as clustering type. Because of this, we need to determine the number of clusters in advance. It is seen here that the number of clusters is calculated by the square root of half of the object number to be clustered. Also, K-means was used as the clustering analysis technique. In practice, it was desired that 81 cities of Turkey were clustered to 26 RPs properly. Therefore, the maximum number of clusters should be 26 and the most suitable cluster value was found to be 14 .

\section{Implementation}

The aim of the established model was to find the best solution by minimizing the costs of collecting and moving the ELT. For this purpose, it was aimed to find out which

Recycling plants (RP) and capacities

TABLE I

\begin{tabular}{c|l|c|c|l|c}
\hline \hline RP & Cities & $C$ [ton] & RP & Cities & $C$ [ton] \\
\hline 1 & Konya & 8 & 14 & Sakarya & 3 \\
2 & Aksaray & 6 & 15 & Kocaeli & 8 \\
3 & Kocaeli & 8 & 16 & Samsun & 5 \\
4 & Samsun & 3 & 17 & Malatya & 6 \\
5 & Ankara & 10 & 18 & Kayseri & 5 \\
6 & Uşak & 6 & 19 & Bursa & 4 \\
7 & Osmaniye & 10 & 20 & Erzincan & 17 \\
8 & Sakarya & 7.5 & 21 & K.Maraş & 5 \\
9 & Konya & 12 & 22 & Kırıkkale & 30 \\
10 & Izmir & 4.5 & 23 & Gaziantep & 15 \\
11 & Sakarya & 6 & 24 & Erzincan & 5 \\
12 & Adana & 4.8 & 25 & Çanakkale & 15 \\
13 & Kocaeli & 5.4 & 26 & Manisa & 12
\end{tabular}

TABLE II

The amount of ELTs (ton) transferred from cities to recycling plants (RP)

\begin{tabular}{|c|c|c|c|c|c|}
\hline $\mathrm{RP}$ & Cities & Amount & $\mathrm{RP}$ & Cities & Amount \\
\hline \multirow{4}{*}{1} & Antalya & 5.252 & \multirow{5}{*}{17} & Elazığ & 0.787 \\
\hline & Isparta & 1.036 & & Malatya & 1.14 \\
\hline & Konya & 1.211 & & Siirt & 0.147 \\
\hline & Karaman & 0.498 & & Batman & 0.322 \\
\hline \multirow{3}{*}{2} & Kırşehir & 0.037 & & Mardin & 0.89 \\
\hline & Niğde & 0.696 & \multirow{4}{*}{18} & Kayseri & 2.52 \\
\hline & Aksaray & 0.825 & & Kırşehir & 0.446 \\
\hline 3 & İstanbul & 8 & & Nevşehir & 0.883 \\
\hline \multirow{2}{*}{4} & Samsun & 2.313 & & Sivas & 1.19 \\
\hline & Tokat & 0.687 & 19 & Bursa & 4 \\
\hline 5 & Ankara & 10 & \multirow{16}{*}{20} & Ăgrı & 0.29 \\
\hline \multirow{5}{*}{6} & Afyon & 1.482 & & Artvin & 0.25 \\
\hline & Burdur & 0.828 & & Bingöl & 0.11 \\
\hline & Denizli & 2.457 & & Bitlis & 0.17 \\
\hline & Kütahya & 0.377 & & Erzincan & 0.36 \\
\hline & Uşak & 0.856 & & Erzurum & 0.90 \\
\hline \multirow{8}{*}{8} & Adana & 2.213 & & Gümüşhane & 0.17 \\
\hline & Hatay & 2.319 & & Kars & 0.42 \\
\hline & Osmaniye & 0.906 & & Muş & 0.29 \\
\hline & Bilecik & 0.468 & & Rize & 0.49 \\
\hline & Eskişehir & 0.033 & & Trabzon & 1.1 \\
\hline & İstanbul & 5.04 & & Tunceli & 0.06 \\
\hline & Kütahya & 0.104 & & Van & 0.64 \\
\hline & Sakarya & 1.85 & & Bayburt & 0.10 \\
\hline \multirow{2}{*}{9} & Antalya & 1.90 & & Ardahan & 0.18 \\
\hline & Konya & 3.44 & & Iğdır & 0.203 \\
\hline \multirow{2}{*}{10} & Aydın & 2.18 & 21 & K.Maraş & 1.43 \\
\hline & Muğla & 2.31 & \multirow{6}{*}{22} & Ankara & 2.47 \\
\hline \multirow{5}{*}{11} & Bolu & 0.829 & & Çankırı & 0.400 \\
\hline & Zonguldak & 1.03 & & Çorum & 1.29 \\
\hline & Bartın & 0.339 & & Kastamon & 0.989 \\
\hline & Karabük & 0.462 & & Yozgat & 0.917 \\
\hline & Düzce & 0.683 & & Kırıkkale & 0.510 \\
\hline \multirow{2}{*}{12} & Adana & 0.967 & \multirow{5}{*}{23} & G.Antep & 2.71 \\
\hline & Mersin & 0.788 & & Hakkari & 0.081 \\
\hline \multirow{3}{*}{13} & İstanbul & 0.566 & & Urfa & 1.6 \\
\hline & Kocaeli & 0.829 & & Şırnak & 0.32 \\
\hline & Yalova & 0.417 & & Kilis & 0.18 \\
\hline \multirow{3}{*}{14} & Bursa & 0.606 & \multirow{3}{*}{24} & Edirne & 1.0 \\
\hline & Eskişehir & 0.681 & & Kırklarel & 0.82 \\
\hline & Kütahya & 1.01 & & Tekirda ̆̆ & 1.7 \\
\hline 15 & İstanbul & 8 & \multirow{4}{*}{25} & Balıkesir & 1.83 \\
\hline \multirow{5}{*}{16} & Amasya & 0.787 & & Bursa & 0.890 \\
\hline & Giresun & 1.14 & & Çanakkale & 1.27 \\
\hline & Ordu & 1.05 & & İstanbul & 8 \\
\hline & Sinop & 0.562 & \multirow{4}{*}{26} & Aydın & 0.114 \\
\hline & Tokat & 0.36 & & Balıkesir & 0.918 \\
\hline \multirow{2}{*}{17} & Adıyaman & 0.681 & & İzmir & 7.70 \\
\hline & Diyarbakır & 1.01 & & Manisa & 3.26 \\
\hline
\end{tabular}


RP the ELT could go to accumulate in the model at 81 cities. The ELT of each province was considered to be $20 \%$ of the number of vehicles. The weight of automobile and truck of tires was $9.1 \mathrm{~kg}$ and $18.2 \mathrm{~kg}$, respectively. The ELT was transported with 25 tons of capacity vehicles. Transportation cost per kilometre for all vehicles was $€ 2$. The RPs and capacities are shown in Table I.

At this stage, the clustering analysis method was used to answer the question of which RP ELT would accumulate in which cities. Analyses was made using the RapidMiner Studio program according to cluster numbers at the specified interval as described under the heading cluster analysis. For the clustering analysis, it was assumed that the clusters formed in the controls were provided with the capacity condition. However, in some cities due to the extra ELT amounts, there are other clusters of ELT shopping for a few cities and plants. The amount of ELT transported to the RPs is as shown in Table II.

\section{Findings and results}

In order to solve the ELT management problem, a MINLP model was proposed in this paper. Also, a clustering analysis method was proposed in order to obtain a solution for the large-scale case study. This method was preferred because it provided with practical and nearoptimal solutions, as well as the fact that it has not been used previously for solving this type of the problem. As a result, 138,753 tons of the ELT was moved to RPs and the cost was found as $€ 1,230,193$.

\section{References}

[1] B.M. Beamon, Logist. Informat. Man. 12, 333 (1999).

[2] B.M. Beamon, C. Fernandes, Product. Plann. Control 15, 270 (2004).

[3] TMMOB, Union of Chambers of Turkish Engineers and Architects, Tire Industry and Petlas Sectoral Report Series 1994.

[4] LASDER, Tyre Industrialists Association (in Turkish). 